\title{
Pubic Warning! Sexing Public Spheres: A Conversation with Shawna Dempsey and Lorri Millan
}

\author{
Lynne Bell \& Janice Williamson
}

This conversation was recorded at the Women \& Texts Conference, University of Leeds, July 1997.

\section{A Pivotal Moment}

Janice: You've said that Winnipeg is the "Lesbian Capital of the Universe." Is that why you moved west?

Shawna: Unbelievably, that's only one of the reasons. In Toronto, we each worked full-time as theatre technicians and I had a restaurant job. We lived in a cruddy apartment from which we got evicted. Being a full-time artist was a pie-in-the-sky dream. But then, suddenly, there was the realization that we could go to Winnipeg with a thousand dollars in our pockets and live for months, whereas in Toronto we didn't have enough for the first month's rent. So, soon after we ended up in Eleanor Bond's Winnipeg living room...

Janice: Your aunt's?

Shawna: My aunt, yes! I applied for a short-term job in Edmonton, so we were going to leave Winnipeg, but Eleanor said, "I thought you came to Winnipeg to be an artist?" I said, "I can't just be an artist!" And Eleanor replied, "Well I am." And I said, 'Oh I know, but you're the only one and you're famous!" And she said, "Well Wanda [Koop] is here," and then started listing Winnipeg women who were full-time artists. It was a pivotal moment-the idea that a person could be a full-time artist was unthinkable because nobody in Toronto has that thought. When we moved back to Winnipeg in '89,Wanda offered to help us look for a studio, but I said, "Oh we don't need a studio! We make our work in our living room." She looked at me like I was crazy, and I looked at her like she was crazy. Imagine renting a whole other room just to make work in-we couldn't dream of doing it. I made my last futon and did my last theatre tech job in '92, the year Lorri and I both stopped theatre tech jobs. 
Janice: So you've been independent artists since 1992?

Shawna: Independently scrambling for funds, but there are funds in Manitoba to scramble for, unlike other places.

Lynne: So you'll keep working as long as the funding is there?

Shawna: Even when it's not we're not going to stop. Not that that should be an excuse for governments to cut arts councils.

Lynne: Can you talk about the potential of performance for cultural activism? It clearly has looser conventions than theatre and more surprises in terms of audience.

Lorri: People talk back.

Shawna: Which is very good. We perform different things at different venues. I just read at a bookstore recently and there was a whole other audience of middle aged people. Like there was an older Chilean couple I would never get to talk to ordinarily.

Lorri: You can coast along pretending you can invite people into art spaces but they don't come, not really. The politic central to our work and our reason for making it is to reach people and proselytize. So we have to go where they are.

\section{No Violence, No Sex, No Profanity}

Janice: Publicity plays such a big role in your spoofs and parodies of advertising. You use media as a publicity machine, a tool to generate and disseminate your work. I'm thinking here of the Winnipeg Free Press coverage/documentation of your intervention at the Winnipeg City Council finance meeting. That public performance was brilliant! ${ }^{1}$

Shawna: Right now we're working on a project called Winnipeg, One Gay City, a fall tourism campaign with bus-shelter ads.

Lorri: The city doesn't know about it yet!

Shawna: No, we haven't been asked to do this.

Lynne: Will you negotiate with the city?

Shawna: We just rent the space, so there's no negotiating at all.

Janice: And they don't ask you what you're going to display in the ads? 
A Conversation with Shawna Dempsey and Lorri Millan · 59

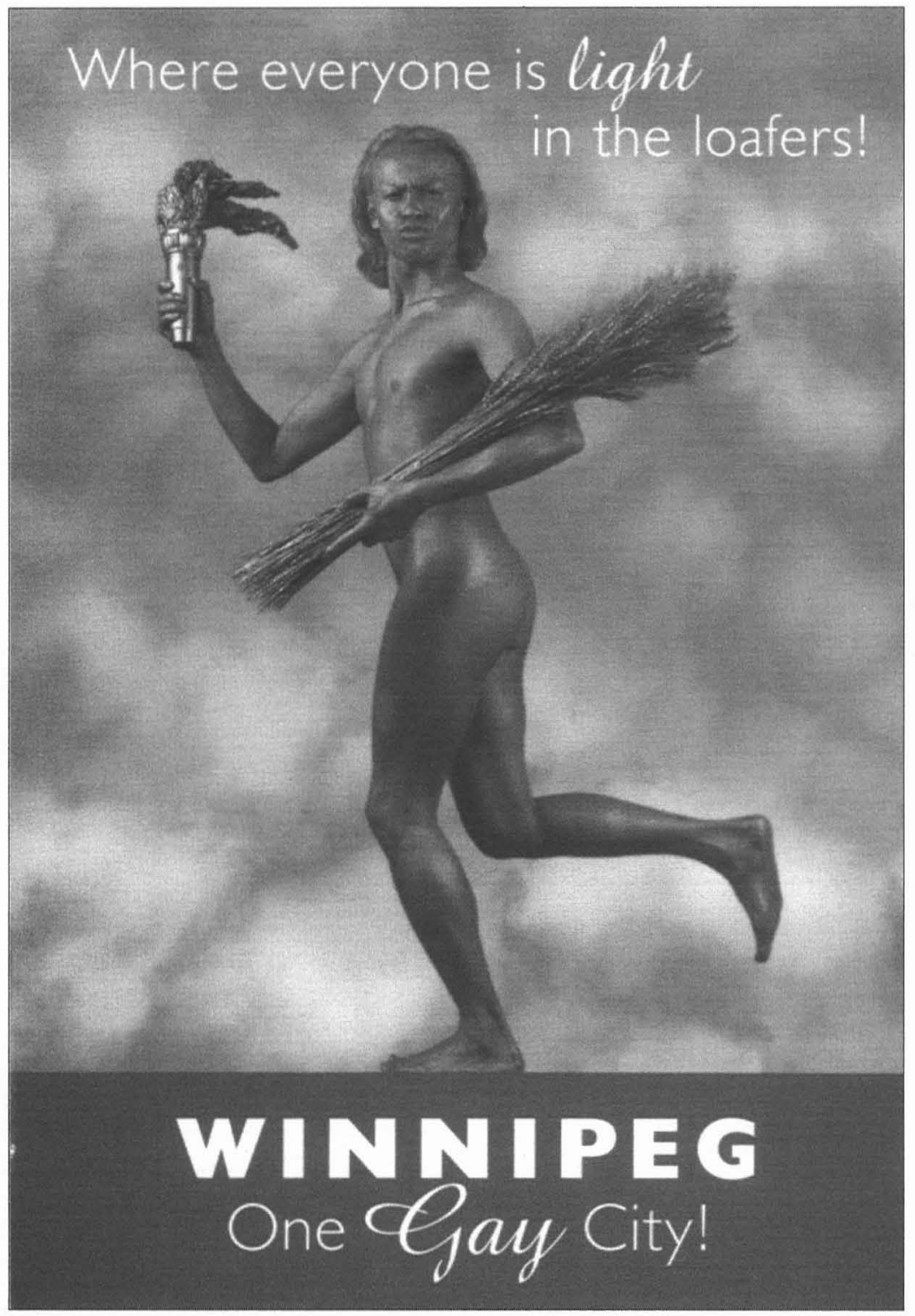

Bus-shelter ad from Dempsey and Millan's Winnipeg, One Gay City project. 
Shawna: I talked to the woman at the company who rents the space and she said, "Oh well, you know, no violence, no sex, no profanity, so you're okay!"

Lynne: Can you tell us about the bus shelter ads?

Shawna: There are three images, all against a blue sky, cloudy and beautiful. One is a Métis woman holding a string of fish with the words "Where the fishing is great!-Winnipeg One Gay City." Another is of a Philippino man dressed as the Golden Boy [a statue atop the Winnipeg Provincial Legislature] holding a sheaf of wheat and a torch, blowing a kiss at the camera with the caption, "Where everyone is light in the loafers!Winnipeg One Gay City." And there is one of a little three-year-old girl with a birthday cake. She's so happy and the caption is, "Where every child can grow up to be whoever they want to be-Winnipeg One Gay City." The idea is that for us Winnipeg is not San Francisco or Puerto Vallarta, but it could be-we could make it that way. Reforming the representation of the city into a gay paradise creates that utopia, hopefully. Or at the very least raises people's awareness about images of advertising.

Janice: How wonderfully subversive it is-the City of Winnipeg should hire you to put it on the international map!

Lorri: People have actually been killed in Winnipeg because they are gay.

Shawna: Instead of hiring us, I think we are going to get into some hot water about it!

Lorri: Really the whole point of a tourism campaign is to bring people in from other cities. So after we do it in Winnipeg, we should post the ads in Calgary and in Toronto and...

Janice: Please do it in Edmonton! When I was writing notes watching the videos today, I meant to quote "Public Warning!" from your A Day in the Life of a Bull-Dyke [1995] and I wrote "Pubic Warning!" That's my imaginary watchword about your work. Your work is risky, but a gallery setting is a safe place for experimentation. In public performances, how conscious are you of the dangers and risks? I've had my home vandalized for teaching lesbian love poems at the University of Alberta, so I'm quite conscious of how public declarations can be dangerous.

Lorri: Yeah, they can be.

Shawna: The stage is such a safe place. Even when I perform in a bar where 
nobody wants to hear me, nobody throws beer bottles at me. We did have a guy stumble backstage once, but he was just drunk. However, after the Ecole Polytechnique massacre I performed in Montreal and stood backstage thinking, "Maybe this isn't such a good idea." On the street it's different and much riskier because there isn't that separation. So for instance, I can't take "Vulva" [We're Talking Vulva, 1989] onto the street at all. I've had men rip parts of the costume off me and take out their penises.

Lynne: That's just pathetic!

Janice: Shades of Gulliver's Lilliputian complex!

\section{Fear Is Contagious, But So Is Bravery}

Shawna: I'm not worried about the Lesbian Ranger piece we are about to do in Banff. For three weeks we're going to be Lesbian Rangers for the Lesbian National Parks and Services [1997]. We look so darned official.

Lorri: And Banff is such a hygienic family fun kind of place. I guess if we patrol at one in the morning when the bars are letting out there might be trouble because there is quite a Yahoo scene there too.

Shawna: We've got uniforms and brochures and hats...

Lorri: ...ranger badges and matching boots. The work is to educate the people about the fragile lesbian eco-system. Because as you know in Banff, through no fault of its own, lesbianism hasn't taken root or...

Janice: ...blossomed? Since Banff is an international tourist site, have you translated your brochure into other languages?

Shawna: Sadly no!

Lorri: It was tempting to get it translated into Japanese but we had to do the project on a shoestring.

Lynne: Are you doing it at the Banff Center or around the town?

Shawna: Oh everywhere! From the minute we arrive to the minute we leave we'll be dressed in our shorts and shirts and baseball caps-our own Lesbian Parks and Services uniforms with insignia.

Lynne: And you have leaflets to hand out?

Lorri: Yeah because we will look so official, we suspect people will ask us for directions. I'm sure if you put us next to a National Parks \& Services 
person you could tell us apart quite easily-so hopefully we won't be arrested for impersonating anyone. But I suspect people will ask us how to get to the Hot Springs or whatever. Our brochure has a map with directions to the Hot Springs and other useful lesbian information.

Lynne: And what would that useful information be?

Lorri: Well how you too can become a Lesbian Ranger and where to find the sites of invisible lesbian history.

Janice: Do you fly up to Lesbian Rangers like in Girl Guides?

Lorri: Good idea! All the rules for joining the Lesbian Rangers are not entirely worked out yet.

Shawna: You have to be a dedicated professional!

Janice: So you're really creating a self-regulating possible world? Are you taking up space as lesbians to counter the way heteronormativity polices your space?

Shawna: It really works. Of course, gays and lesbians do get bashed and there is violence, but if we lived our lives the way we wanted to...

Lorri: Fear is contagious, but so is bravery. It has to be.

Janice: ...and pleasure and fun. I mean your work is so playful and humorous.

Lynne: You use humour constantly as a critical tool?

Lorri: Well yeah, that's the only way we could perform in a bar ever. Humour is the only way to force people to hear what they don't want to hear.

\section{Arborite Culture!}

Lynne: So many of the lip-sticked and aproned images of heterosexual femininity that you deconstruct come from the late 1960s. Why do you focus on this particular historical landscape?

Shawna: It's our mothers' world. And we take our mothers and their peers and make them into complex icons. In most of our work we take icons and make them say what we want them to say. So, for example, we take the Medusa, really a horrible mythological story, and make it say what we want it to say. Or we take the mother/housewife and make the icon say what we want it to say. 
Lorri: We invent a powerful character when we reinvent those that already have such weight in our culture. We're not writers. Making plays with laudable contemporary characters doesn't interest us. It's more interesting to pick out things from our histories or mythologies and turn them around.

Shawna: This is not unlike what many Women of Colour are doing-recreating their history and making it relevant. Sometimes White women think, "Oh, well we don't have a culture," but, of course, we do we have this huge culture...

Janice: Arborite culture! How much of your research is actually interviewing women?

Lorri: None! We make it all up!

Janice: The cultural icons are available to you through...

Shawna: Mass media, movies, magazines, churches...

Lorri: ....and our mothers...

Shawna: ...our own histories and childhood memories.

Janice: What do your mothers think about your work?

Lorri: Mine's dead...

Shawna: Mine's dead too!

Janice: That's very sad, but I wonder if their absence liberates you to do your work somehow?

Shawna: Probably it is liberating.

Lorri: I think it is, sadly, not that they wouldn't like who we are...

Shawna: They would love us!

Lorri: But I know that when my mother died, there were all the usual hallmark tragic elements to it-it was so unexpected. But sadly, there was this unexpected freeing aspect. Our mothers' deaths do certainly inform our relationship and our collaboration.

\section{Where It Goes, Or, Who Did What?}

Janice: You talk about your collaborative work not just in terms of sharing, but something else happens. Your work together is more than the sum of its parts. 
64. Tessera

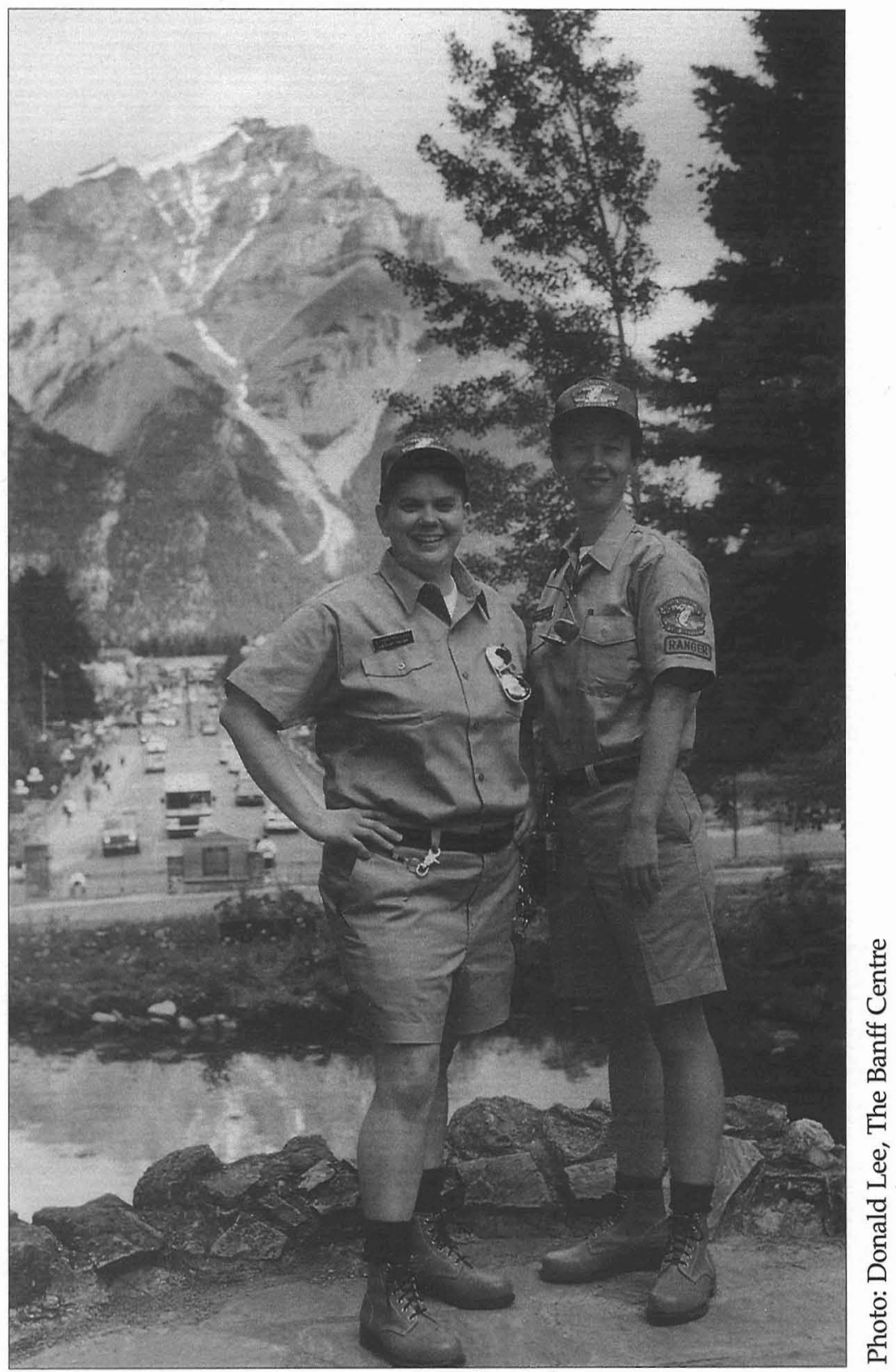

Rangers Shawna Dempsey and Lorri Millan, July 1997. 
Shawna: We own a house together with two other people. So we're almost always together and chatting. Part of the wonderful thing about being an artist is we can get up for breakfast and say, "Wouldn't it be neat if...?"

Lorri: And the other one doesn't go, "That's stupid!" We can make it happen! It snowballs. So by the end, we've got this boulder and we don't know where it began or who contributed what.

Janice: What kind of individual skills do you bring to your collaboration?

Shawna: I do most of the business and Lorri is more technically adept. Usually I do the first draft of a text and Lorri will re-write it or say, "It's no good. Throw it in the garbage." Or "edit it." Or "This one sentence is good."

Lorri: Shawna's primarily a performer and not an actor. It's a matter of finding a voice that she's comfortable with. Before we actually proceed with a piece comes the costume. If it's not a costume, it's a visual idea. $A$ Day in the Life of a Bull-Dyke was actually a magazine spread that we created. Then we went through all the processes involved in making it real. There's always some visual aspect that comes first and then Shawna usually writes a draft. After a couple of years, where it goes or who did what is quite hard to tell. Some of the work we do now might actually be stemming out of a conversation we had five years ago!

Shawna: Don't you think generally speaking, you will have the first germ of an idea or a visual concept?

Lorri: Yeah, you could break it down especially in terms of the media work-I tend to think more in terms of film or video-so we have different strong suits. Shawna as a performer has certain instincts that she brings to the work.

Shawna: When we are rehearsing, it's very collaborative and there really is no directorial role. Lorri may say, "Oh that doesn't look right." And I'll say, "Well it feels good," and she'll say, "No, that's stupid, try something else." Or I'll say, "No that feels bad I can't do that." So it's very collaborative.

Janice: You're operating with informed intuition that comes from your working experience and knowledge of each other...

Shawna: Yeah, but we also don't know why things work out. Why does our Mary Medusa [1992-3] work? 
Lynne: She is so brilliant with her headdress made of plastic snakes...

Lorri: It's 100 snakes attached to a baseball helmet.

Janice: You really want to hate Mary Medusa but as the piece goes on her contradictions are more appealing and my anxiety as a professional woman rises since of course I'm implicated in her satirical drama.

Shawna: Perhaps more clearly than any of our pieces, our Arborite housedress piece does that too. The woman is racist and small-minded in her house-dress fortress but she is clearly in a prison and you know her vulnerability. We all have those contradictions.

Lorri: Especially as lefty First-World people. Feminism hugely informs our work but so does being in a First-World culture.

\section{How To Create A Bigger, Better, Larger-than-Life Lesbian}

Lynne: What was your original inspiration for A Day in The Life of A BullDyke, which exists both as a publication and a video?

Lorri: The original idea was the Life Magazine format, not the video. By the time we had organized the photo shoot, we realized how enormous the project had become. Just on a whim we thought, we'll bring a Super 8 Film camera along and get a photographer friend to shoot some material. So it was literally an afterthought. Not all of it turned out. We went away with the footage and wrote the script around the usable stuff. Then we shot the additional scenes that are inserts. So the script came after the visuals.

Lynne: In your parody of Life Magazine entitled In The Life: Portrait of A Modern Sex-Deviant, Sal becomes the object of a Life photographic case study with a 60 s look to it. In this mock version of a vintage Life Magazine, Sal's story is told from the perspective of a patronizing journalist. But the video, A Day In The Life Of A Bull-Dyke, is narrated through Sal's autobiographical voice. Why the switch in voices?

Shawna: Well we couldn't do a mock Life Magazine and put our own voices in there. So we had to stick to the form we were parodying.

Lorri: And having finished the mock Life Magazine, we knew there was something else we wanted to say. The obvious choice in our minds was, "What would Sal have to say about it all?" One of our goals was to talk about the cultural hysteria around lesbianism and the idea of the monstrous woman. So we latched onto this Bull Dyke character as a popular 
cultural example of a monstrous woman. When we gave Sal a voice, we had to struggle with our own cultural stereotypes around butch/femme. We needed to find an interesting way to make this character talk. Rather than have Sal as a female James Dean muttering monosyllabically, we wanted to create a heroine- to take the power of this humanized character and create a bigger, better, larger-than-life lesbian.

Shawna: A lot of our work deals with monstrosities and the grotesque. Really we're all the monsters because the rules of normal are so tight. No matter how good we try to be we can never be good enough!

Janice: The saxophone and piano jazz music composed by Marilyn Lerner remakes film noir and the Dashiel Hammett style of the script itself reminds one of those great 50 s murder mysteries. When you're working in different media, you are obviously playing with different conventions. What's your strategy?

Shawna: Well it's just finding the one that seems to work, whether it's the most natural choice or not. Sometimes we'll have a problem and say, "Okay what's the most likely solution," and then we look at options.

Lorri: It has to do with playing with the icons. We like to find forms to put people at ease, so whether it's the Arborite Housewife or the Bride or Sal in her butch drag, you recognize the character and add in the mix and sound from movies we've all seen a million times. With Sal, we want you to know that this is an anti-hero, an underdog, and we're supposed to like this character. So right off the bat, we've done away with a lot of character development and a lot of narrative business. People are drawn in because we speak popular culture language, and then we surprise them: Sal is not 'just' a woman, she's a butch lesbian. Every time she opens her mouth, she says something that perhaps most would find unpleasant. But still the work is inconclusive. We start on a footing that says, "Yes we have all come from the same fucked-up place, we've all grown up fucked up heterosexuals on this continent in the last half of this century." We reference television and movies and lots of other things as a common language, a strategy...

Janice: To familiarize the audience with what they may find strange or even frightening.

Shawna: We also work with many people. There's the myth of the solo artist and things springing from his mind. We already violate the myth because there are two of us. People often want to separate or ask, "Who really is the artist?" 
Lynne: I'm thinking how agency or the ability to make something happen is often a collaborative effort.

Shawna: Yes, and fortunately for us Winnipeg has a very sharing, collaborative community.

\section{Really Big Lesbian Cultural Touchstones}

Lorri: We are very much engaged in building a culture as lesbians right now. In the last fifteen years we've seen an explosion of culture building. Shawna and I don't make documentaries or create contemporary narratives. We want to create venues for ideas so we often pick something with a strong aesthetic. Whether it's nostalgic or a fantastical visual element, we remind our audience again and again that this isn't real.

Janice: This reminds me of the fictional dramatized episodes in Lynne Fernie and Aerlyn Weissman's Forbidden Love where they take lesbian pulp fiction of the 50 s and make it generate a liberatory narrative of lesbian desire.

Lorri: Forbidden Love had a very big impact. Most lesbians in North America have seen it. And it is recognizable all over the world. We wear pins that say Forbidden Love and people recognize them all over the place. It is one of a handful of really big lesbian cultural...

Shawna: ...touchstones!

Lynne: What other theorists, performers or artists have influenced your work?

Shawna: Judy Radul is a poet and performance artist in Vancouver and an inspiration. Every time I hear her read, I'm inspired to write better. Or Morley Baden this art professor in Victoria who tells his students, "Whatever you do, do it as big as you can-go all the way with whatever your idea is." His students told us that he says that, and that's always really stuck with me. Whatever it is, we try to take it as far as we can! The Clichettes, the Toronto feminist lip-synch performance group were also hugely influential on us during the 80 s when I worked with them as a technician.

Janice: And what about Tanya Mars whose work like yours centres a lot around fantasy costume and a moving tableau vivant?

Shawna: Absolutely. And Lynn Carter in Toronto also did costume work 
and sculpture using dress and costumes. Plus Lorri and I both worked for Nightwood Theatre [a Toronto feminist theatre company].

Lynne: Do you read feminist theory?

Lorri: We go through spurts of reading that sort of material. And then find ourselves busy making the work.

Shawna: We've read a fair number of essays about cross-gender work.

Lorri: Usually we read around specific areas that we are interested in at the time. When we were doing the Arborite Housewife, we read a wide range of material about women in architecture. But we're really low brow you know.

Lynne: Popular culture is your archive...

Janice: ...and you are able to make a bricolage. You borrow and steal from popular culture in a collage politics of the everyday. You take a moment in history and push it. In the Object/Subject of Desire, you even spoof feminist theory by making it into a video costume drama.

Shawna: Our politics are connected with our struggle to be artists and with being really 'out.' Our everyday existence is mired in these issues...All women experience resistance.

Lorri: Yeah-resistance might come later for some. But the need for feminism is still a reality of women's lives.

\section{A Woman Out of Control Is A Frightening Thing}

Lynne: The refrain in your Mary Medusa performance is "A woman out of control is a frightening thing." At the end of the piece, you squash a chocolate cake between your thighs...

Lorri: Sticks with you doesn't it?

Shawna: That scene is part of a much longer 40-minute piece. We did that and Mermaid In Love [1990] as a double bill for two weeks in Winnipeg. The local TV station said, "Come on down!" and we'll give you a live spot on the entertainment newsmagazine show. So we did that excerptthough I edited "she doesn't give a fuck" out of it.

Lorri: They were really nervous about swearing!

Shawna: "No profanity, okay? No profanity." Anyway I squished the cake 
live, on-air. Immediately the phone rang!

Lorri: The station head was so livid and emotional that he couldn't speak. All he could say was "the cake" over and over again. Well the producer lost his job right there, got fired on the spot. I guess there were a lot of phone calls complaining about it throughout that evening. But it was his inarticulate rage that really made us realize that it had this dream image potency and clearly touched on some serious taboos for people.

Shawna: Actually Pauline Greenhill, our anthropological theorist in Winnipeg, wrote a paper about it. She wonders whether it's a scatological reference because of the chocolate cake. It is such a weird episode to get that strong of a reaction.

Lorri: I think it's taboo because the scene is such an unabashed display of desire and appetite in a woman.

Shawna: And destruction too!

Lorri: It's her vagina and sex, food, and everything we are supposed to have control over and restraint around. And the snakes on top of Mary Medusa's head just send people over the top.

Lynne: And it's so unexpected! On stage, or across the video screen, this luscious cake advances-it's really hilariously disturbing.

\section{That Moment Of Instability...}

Lorri: Nine times out of ten when people say they love our work, they're talking about our videos and don't even realize we do performance. This means video is getting out there in ways that we couldn't accomplish through performance since we can't be in many places at once. However...

Shawna: ... performance is what we love to do because it can change people-just that moment of instability...

Lorri: ...and it may only last a minute. The reality of performance is that you've only got between thirty seconds and five minutes where you can really get people and keep them where you want them. During that time anything can happen. You can take them anywhere. Whether it's connected to some sense of heartbeat and mortality or whether it's because we are actually sharing time together, there's something about having that body stand in front of you and tell you something... 
Shawna: ....and being allowed to look at the other human being.

Lorri: We're an oral, story-based culture. Plus Canadians are much too polite to walk out of live shows generally speaking, so it's a great way to imprison them! A captive audience! The same people have no problem walking out of a movie theatre or switching off the TV.

Shawna: So many women do performance because we are used to being watched or appraised. When we are performing we can say, Okay you can look at me, but I'm going to tell you what to think.

Janice: When you did your Much Music video What Does A Lesbian Look Like? [1994] to challenge stereotypes and promote alternative representations, why did you chose video and television?

Lorri: Much Music came to us actually. They were putting together a spoken word series modeled after one on MTV in America. Spoken word for the last several years has been quite a popular form and they wanted to address literacy and use poets. Though they didn't want any of us to talk about literacy, they wanted us to use literary or poetic forms to talk to kids about our ethnicity. We were the lesbian ethnics. Faced with the fact that there was no money to do the video-no resources were given to us-and that they were going to cut together whatever footage we made, our idea had to be unfuck-up-able. What you see in the end is their shooting, their editing, their tag at the beginning and end, and their style. So we had to design something they couldn't really mess up too badly and something that appealed to their audience of primarily ten to fifteen-year-olds. The video was broadcast absolutely everywhere in Canada from the North West Territories to suburban Ontario. What the heck does a ten-year-old think about lesbians if they think anything at all? We just wanted to talk to them about something that they might have experienced-obviously they've probably come into contact with various stereotypes somewhere along the line.

Shawna: And we had to make it somewhere where there was a Much Music crew-Toronto or Montreal or Vancouver-because they were not willing to fly a crew anywhere.

Lorri: We had exactly a minute of air time and if we were over 60 seconds then they might edit it down. They didn't want to give up too much because every broadcast minute has a dollar value on it. And yet they wanted the cachet of being able to pat themselves on the back for producing 
it. And if they didn't like it, they didn't have to play it. Instead of fighting the Much Music form, we decided to use it. On the face of it, it is in the style of a music video but filled with faces you never see-Montreal lesbians of every stripe.

Shawna: Every unemployed Montreal lesbian and bisexual who could be there on a Thursday afternoon.

Lorri: And as a result of this Much Music video short, we have this very young audience now... When we perform, we have these young women, $18,19,20$ years old who come up and say this piece was helpful for them in terms of coming out in whatever little small town they were in. And it has started them on their current riot girl paths. So there is another stream of young females out there.

Shawna: Sometimes they will come up to us in a bar and say, "I just want to tell you I really liked your video." And we will say, "Oh We're Talking Vulva?" And they say, "No, What Does A Lesbian Look Like?" They're too young to remember the Vulva piece. We are always questioning whether we should do these TV things and to what extent do we sell our souls? TV is such an overwhelming commercial experience. Can you subvert something un-subvertable? On the other hand, I don't think we have a lot of choice since we do have to try it as a medium even though we don't have to really tie our future to it.

Janice: This is Kim Sawchuck's point about women and the 'information highway'. In her talk, she dresses up with maple-leaf blindfolds and walks a thin yellow line to demonstrate her point. While you can't undo the corporatist interests in the internet, you can graft on something else that will enable it to mutate into something useful to women-disruptive, transgressive and pleasurable.

\section{Crafting Those Complicated Stories}

Shawna: For me the most pivotal thing anybody has said at this conference was [Okanagan writer] Jeannette Armstrong's comment: "For my people, stories are everything." It's all about sharing and the story is more than the model, it's life and the ultimate reality, and truth. You know-the power of words-I believe it!

Janice: And images? They seem to propel a lot of your work.

Shawna: Well yes! But they are narrative! 
Lorri: People insist on constructing narratives for anything they experience. But sometimes images are puzzles. We talked briefly about how the crushing of the cake has a dream-like resonance for people. You might not know exactly what it means or why it stuck with you. Maybe it solicited horror, pleasure or this desire to run home and buy a chocolate cake. I don't want to know what you do with it!

Janice: I'll never eat chocolate cake again!

Lorri: Or you'll only eat chocolate cake. This visual aspect as strategy and the actual pleasure of writing is why we are artists. That's why we are not politicians or social activists organizing rallies. Those visual elements and writing the actual text is so important. We do what we do because we love crafting those complicated stories and we are passionate about doing it.

Janice: Critics have been writing about the way corporations appropriate liberatory slogans from feminism or the civil rights movement to advertise goods and services. You work in a parallel process from the other side by using publicity and advertising as subversion.

Lorri: Or to sell feminism! Or utopic desires and worlds. Because it is incredibly successful in every culture, advertising can teach us that we can embrace-Build it and they will come! Say it, believe it and we can make it so. Our agenda is just a little different. We don't want to leave room for negotiation in terms of social justice.

\section{Accessibility Is Lucidity, Not Simplicity}

Lorri: Our approach to each form is similar even though we have had to acquire many different kinds of skills to make each happen. We don't really approach a billboard project any differently than we do anything else. We have the same considerations of content, audience, lucidity-and the same questions: How does this form support this idea? Is it in the right form? That's often how we work: we have an idea and try to find the form that best supports the concept. One of the advantages of our performance work is that it has really benefitted by our enormous contact with the audience. After performances, we have actual conversations with people about what they do and don't understand. If you're just creating objects and they go out and tour on their own, you don't have that kind of interaction and you don't really have a sense of where you're succeeding, and where you're being frustrated.

Shawna: Lucidity is one of our big concerns and it has a nice spin off in 
that it makes our work accessible. Accessibility is lucidity, not simplicity. I use an audience's response to hone the work. Even if the audience's comments aren't that literal. When I'm performing, I know when that woman from Paris or from New Zealand laughed. And I know when I hit it and when I don't. I use those cues to make it better the next time.

Lorri: You know something electric is happening or not and it translates into all the work. It's a skill that you become attuned to like hearing notes on a scale or being able to tune a guitar. You have to acquire a sense of communication. Hence wildly different venues are possible for us.

Janice: Your performances and videos work on various levels and have a powerful initial visual impact. You've talked about being in an 'erotophobic' culture, and your work confronts this head-on with explicit interrogations of sexuality and desire and cultural stereotypes. But your work also overtly critiques class with the working class bull dyke figure Sal and through Mary Medusa's uppity professional middle-class women's desires. You manage to critique the class stereotypes while maintaining some compassion for those who inhabit these zones.

Shawna: Class is a huge category and I don't think we acknowledge it culturally...

\section{Lorri: ...anymore. Yeah!}

Shawna: No, not so much since the early sixties. People get really defensive about it, but class has a huge influence on whether we are allowed to do what we want to and on how others respond to us. Class position is often present in our work when characters talk about their restrictions and possibilities.

Lorri: Quite a few of our characters are straight women and that baffles people. We have never really thought about why Medusa is a straight woman because she's just somebody we wanted to talk about. Sometimes as feminists we get into competitive situations like 'the Bull Dyke is the most repressed woman on the planet.' Well, you know...

Shawna: That doesn't matter a whole lot.

Lorri: We are all equally shafted-well, maybe not equally shafted, but we're all thoroughly shafted anyway.

Janice: ...in unequal ways. 
Lorri: So we choose different personae to explore and write about different ways in which we're shafted.

Janice: Though Mary Medusa does get the cake.

Shawna: Yeah, and she gets the last laugh!

\section{Basic Educational Tools}

Janice: After We're Talking Vulva, Canada Health should hire you to make sex education videos. Your video provides everything from orgasm to the hygienic way to wipe your bum-basic educational tools.

Shawna: Well Planned Parenthood actually called us to see if we would be interested in making a film about sexuality for teenage girls. We told them we had already made that film, "Have you seen our We're Talking Vulva?" The woman on the phone said, "Oh yes, but this is our problem. To get it into the schools, there can be no reference to abortion, homosexuality or masturbation."

Lynne: Whose rules?

Lorri: The schools, the Province of Manitoba.

Shawna: Even to introduce the idea that sex should be fun for girls is very challenging.

Lorri: Completely out of the question!

Janice: Why did she call you?

Shawna: Exactly!

Lorri: That was our response. We thought for about five minutes, but it seemed like an impossible task. How can you educate?

Shawna: Instead we try and put Vulva into the hands of teachers who sneak it into the classroom.

Lynne: And do they?

Lorri: Yes, we've heard stories to that effect.

Shawna: It's played on TV too. Women's Art Resource Center in Toronto has a copy and they've got a women artists program that they take to schools, so it gets slipped in. 


\section{Forming A Citizen}

Janice: Lorri, while you talk about your history as a high-school dropout, you have a very powerful pedagogy as an artist/public educator.

Lorri: High school is very little about education and mainly about forming a citizen or non-citizen. That's what I couldn't take in the end. It wasn't because I couldn't cut the academic thing. I found it exceedingly boring and wrong. So why continue it? It was also a source of a great deal of persecution. It made less and less sense to be there and I got a theatre job.

Janice: That's the history of so many gay and lesbian teenagers in high school where hideous homophobic harassment goes on.

Lorri: I was beaten up a lot and it still really hurts. Isn't it something like three out of five youth suicides are gay and lesbian? It's sickening.

Janice: What about your educational experience Shawna?

Shawna: I went to York University to do fine arts studies specializing in experimental directions. Toby McLennan was a pivotal professor there.

\section{Very Prairie}

Janice: Would you define yourselves now as prairie artists?

Lorri: Oh absolutely!

Janice: How has your life on the prairies changed or informed your work?

Lorri: Well, I don't think we could have done it in Toronto. We wouldn't be collaborating and we wouldn't have created the same body of work.

Shawna: You're right, we probably wouldn't collaborate because we'd be competing against each other.

Lorri: There's a hardness to life in Toronto and there's a kindness to the Winnipeg community that is not sentimental. It is simply a bunch of people who want to make work, see other people's work and live in a community that is actively involved in artistic dialogue. And it is very mixed, disciplinary-wise. This doesn't happen so much in bigger centres.

Shawna: In April we decided we were going to make this video The Headless Woman. We had been tossing this idea around and decided, Okay, let's just do it. We don't have any money but we have room on our Visa card. We called set painters, visual artists, stage managers, playwrights, film makers. People came and helped us happily to make the video. 
Lorri: There are other places with communities like that, but Winnipeg is the right size with the right sort of cultural history. And it has still got enough arts grants and cheap rents so there is not the same feeling of panic or scarcity. As artists we have a sense of luxury in one of the poorest provinces in Canada, second only to Newfoundland.

Shawna: We've got a nice big place to live with other people and a 1963 Pontiac.

Lorri: We've got beaches just a little ways away and the sun. The 1919 Winnipeg General Strike is alive in everyone's hearts mythologising the city as a place where things can happen and change. Where the little people can make it happen. It's collectivism coming back. There's a tremendous amount of pride about that sort of socialist working class history.

Shawna: Well, we're all marooned there together!

Lorri: I don't know what it is, but it's not as isolated a feeling as in some other smaller cities in Canada. There is a real sense of it being connected to a larger art community. Artists come and artists go, and cross-fertilization happens. It's unique. In Toronto you may or may not see a show, may or may not meet the artist. Come to Winnipeg and you meet everyone at parties or at a studio drop-in or at your opening. Exchange really happens.

Janice: What about the different art spaces in Winnipeg? The Winnipeg Art Gallery has a tradition of showing innovative contemporary Canadian art as well as the active parallel galleries.

Shawna: Artists are also into organizing. Szu Burgess who shot $A$ Day In the Life of a Bull-Dyke decided there should be a lesbian film and video festival-not a gay/lesbian festival or a woman festival. But a lesbian festival, and she organized it by programming people from all over the country.

Lorri: Or artists decide they've seen someone's work in another city that they should bring in and suddenly they'll curate a show. No one waits around because curating is someone else's job. People just get things done, which is very prairie!

\section{Notes}

${ }^{1}$ As the Golden Boy, the symbol of Manitoba, Shawna (with press in tow) stormed a City of Winnipeg finance committee meeting to award Al Gordon (crafty city councillor) the first Golden Boy Award for Unscrupulous Political Action (1993). 